\title{
Costs of New Atypical Antipsychotic Agents for Schizophrenia: Does Unrestricted Access Reduce Hospital Utilization?
}

Coûts des nouveaux agents antipsychotiques atypiques pour le traitement de la schizophrénie : l'accès libre réduit-il les taux d'hospitalisation?

by DARIA O'REILLY, MSC, PHD

Program for Assessment of Technology in Health (PATH), St. Joseph's Hospital Department of Clinical Epidemiology and Biostatistics, McMaster University Hamilton, ON

DAVID CRAIG, MD

Department of Psychiatry, Memorial University of Newfoundland

St. John's, NL

LESLIE PHILLIPS, PHARMD

Faculty of Pharmacy, Memorial University of Newfoundland

St. John's, NL

RON GOEREE, MA

Program for Assessment of Technology in Health (PATH), St. Joseph's Hospital Department of Clinical Epidemiology and Biostatistics, McMaster University Hamilton, ON 
Costs of New Atypical Antipsychotic Agents for Schizophrenia

JEAN-ERIC TARRIDE, PHD

Program for Assessment of Technology in Health (PATH), St. Joseph's Hospital

Department of Clinical Epidemiology and Biostatistics, McMaster University Hamilton, ON

PATRICK PARFREY, MD

Clinical Epidemiology Unit, Memorial University of Newfoundland

St. Jobn's, NL

\begin{abstract}
Objectives: To determine whether increased expenditures to provide unrestricted access to expensive atypical antipsychotic drugs would be associated with a reduction in hospital utilization and cost by patients with schizophrenia. Secondary objectives were to determine the factors associated with length of stay (LOS) and readmission for schizophrenia sufferers.
\end{abstract}

Methods: Retrospective chart review identified all acute hospitalizations for schizophrenia in the province of Newfoundland and Labrador. LOS and readmission rates, as well as risk factors influencing them, were measured during three time periods: (1) 1995/96, beginning of restricted access; (2) 1998, last year of restricted access; and (3) 2000 , second year of open access. Average per diem costs were multiplied by LOS to determine hospital expenditures, and the provincial drug plan database provided the amount of money reimbursed for antipsychotic drugs.

Results: Days of hospitalization for schizophrenia totalled 15,089 in 1995/96, 16,318 in 1998 and 15,691 in 2000, resulting in per annum costs of $\$ 6,474,095, \$ 7,080,065$ and $\$ 6,615,795$, respectively. There were $57(18.2 \%)$ fewer patients hospitalized and 98 (16.7\%) fewer admissions during open access (2000) when compared to a period of restricted access (1995/96). However, median LOS in 2000 was significantly longer than in 1995/96 (22.0 vs. 15.0 days, $\mathrm{P}<0.001$ ), and was independent of other factors significantly associated with LOS (e.g., suicidal ideation on admission). No change in the number of readmissions was observed. Government expenditures for atypical agents were $\$ 217,273$ in $1995 / 96$ and $\$ 3.8$ million in 2000, a 17.5-fold increase.

Conclusions: The unrestricted reimbursement policy for atypical antipsychotics was associated with a large increase in drug plan expenditure, which was not offset by a decrease in hospital utilization by schizophrenia sufferers. Although a decrease in hospital admissions occurred, any associated savings were negated by an increase in LOS. 


\section{Résumé}

Objectifs: Déterminer si l'engagement des fonds nécessaires pour assurer le libre accès aux médicaments antipsychotiques atypiques dispendieux s'associerait à une réduction des coûts et du recours aux soins hospitaliers par les patients atteints de schizophrénie. Les sous-objectifs de l'étude avait pour but de cerner les facteurs associés à la durée du séjour et à la réadmission des personnes atteintes de schizophrénie, ainsi que la consommation de médicaments antipsychotiques atypiques et leur coût pour le gouvernement.

Méthode : Leétude rétrospective des dossiers hospitaliers a permis d'identifier tous les cas d'hospitalisation aiguë pour schizophrénie dans la province de Terre-Neuveet-Labrador. On a mesuré la durée du séjour et le taux de réadmission, ainsi que les facteurs de risque qui influent sur ces variables, pour trois périodes différentes : 1 ) 1995-1996 - début du système d'accès restreint, 2) 1998 - dernière année de l'accès restreint, et 3) 2000 - deuxième année de l'accès libre. Pour évaluer les frais d’hôpitaux, on a multiplié le coût moyen par jour par la durée du séjour, et on a utilisé la base de données du régime d'assurance-médicaments provincial pour calculer les sommes remboursées pour des médicaments antipsychotiques.

Résultats : Le nombre total de jours d'hospitalisation pour schizophrénie sélevait à 15089 en 1995-1996, à 16318 en 1998 et à 15691 en 2000, ce qui a entrainé des coûts annuels de 6474095 \$, 7080065 \$ et 6615795 \$ respectivement. Le nombre de patients hospitalisés a diminué de 18,2 p. cent (57 cas de moins) et le nombre d'admissions, de 16,7 p. cent (98 cas de moins) pendant la période d'accès libre (2000) par rapport à la période d’accès restreint (1995-1996). Cela dit, la durée médiane du séjour était considérablement plus longue en 2000 qu'en 1995-1996 (22 jours comparativement à $15, \mathrm{P}<0,001)$, indépendamment d'autres facteurs fortement liés à la durée du séjour (p. ex., idées suicidaires au moment de l'admission). Aucun changement náa été relevé dans le nombre de réadmissions. Les dépenses gouvernementales pour les antipsychotiques atypiques se sont multipliées par un facteur de 17,5 entre 1995-1996 et 2000, passant de 217273 \$ à 3,8 M\$.

Conclusions : La politique de remboursement sans restriction des antipsychotiques atypiques a entraîné une sérieuse augmentation des dépenses du régime d'assurancemédicaments, augmentation non compensée par une diminution du recours aux soins hospitaliers par les personnes atteintes de schizophrénie. Bien qu'on ait constaté une réduction du nombre d'admissions, les économies ainsi réalisées ont été annulées par l'augmentation de la durée du séjour. 


\section{卫} he burden of schizophrenia is considerable. Although the disease occurs in only $1 \%$ of the general population (Hafner and der Heiden 1997), it has a much greater impact on healthcare costs than the prevalence rates suggest (Goeree et al. 1999). The disease has an early age of onset, causes longterm morbidity and necessitates maintenance drug therapy and frequent admissions to hospital. In 2004, the total financial burden of schizophrenia in Canada was estimated at $\$ 6.85$ billion, with the direct healthcare and non-healthcare costs estimated at $\$ 2.02$ billion (Goeree et al. 2005). The majority of this cost was for acute (23\%) and nonacute $(38 \%)$ hospital care.

At present there is no cure for schizophrenia, and antipsychotic medication is the cornerstone of treatment. These drugs help manage the symptoms of the disease and delay or prevent relapse. In the last decade, new "atypical" antipsychotics have been introduced. Compared to the older "conventional" or "traditional" antipsychotics, these medications appear to be equally effective for helping reduce such positive symptoms as hallucinations and delusions (Beasley et al. 1999; Schillevoort et al. 2001; Lieberman et al. 2005), but may be better than the older medications at relieving the negative symptoms of the illness (e.g., social withdrawal, lack of motivation) (Baldwin and Montgomery 1995). The primary advantage of these new drugs is the decreased risk of developing extrapyramidal side effects (EPS) or movement disorders (Beasley et al. 1999; Schillevoort et al. 2001). It has been argued that medications with fewer and milder adverse effects may increase adherence and thus improve effectiveness when used in clinical practice (Glazer and Johnstone 1997; Kane 1999; Lindstrom and Bingefors 2000; Chakos et al. 2001). As a result, the value of reduced or absent side effects may have economic implications by reducing the need for hospital admission that may justify the higher acquisition costs associated with atypical antipsychotic medications. In fact, two Canadian economic evaluations concluded that clozapine and risperidone produced an annual cost savings of \$389 million and \$662 million respectively, with most of the savings due to reduced hospitalizations, offsetting the associated incremental increase in drug costs (Oh et al. 1996).

The Newfoundland and Labrador Prescription Drug Program (NLPDP) provides prescription drug coverage for all residents of the province who are either receiving social assistance or are aged 65 or older and in receipt of the Guaranteed Income Supplement (GIS). Prior to December 1998, the NLPDP relied on a restricted-access policy for atypical antipsychotic medications. Reimbursement was based on defined criteria: a diagnosis of schizophrenia and either failure to respond to two adequate trials of conventional agents, or intolerance of conventional agents. In 1999, the Department of Health and Community Services, Government of Newfoundland and Labrador introduced an unrestricted reimbursement policy for four of the newer atypical antipsychotic medications: risperidone (Risperidal $\left.{ }^{\circledR}\right)$, clozapine $\left(\mathrm{Clozari}^{\circledR}\right)$, quetiapine (Seroquel ${ }^{\circledR}$ ) and olanzapine $\left(Z_{\text {yprexa }}{ }^{\circledR}\right)$. The decision was influenced by a 
combination of factors, including mounting pressure from the schizophrenia community, psychiatrists, the pharmaceutical industry, the media and, more significantly, by the observation that the increased drug acquisition costs could be offset by decreased hospital utilization (Oh et al. 1996).

An important aspect of the policy change was that it depended upon an evaluation of the policy by an independent academic research group sponsored by the four companies that produce each of the atypical antipsychotics affected by the policy. The decision was to be revisited pending the results of the evaluation. This current evaluation is significant in that it represents the first time the NLPDP has evaluated the impact of a policy decision on another healthcare sector.

The primary objective of this study was to determine whether the increased expenditure for unrestricted access to expensive atypical antipsychotic medications would be associated with a reduction in hospital utilization and cost for schizophrenia in the province of Newfoundland and Labrador. The main hypothesis was that as a result of unlimited access to atypical antipsychotic medications, the additional cost of such drug use would be more than offset by a reduction in hospitalization costs through reduced admissions and length of hospital stay (LOS) for persons with schizophrenia.

Secondary objectives were to determine the factors associated with LOS and readmission for schizophrenia sufferers.

\section{Methods}

The consequences to the healthcare sector of replacing the prior authorization program with open access to atypical agents were assessed using a pre-post design. This research project was designed to evaluate two separate but related issues surrounding unrestricted access to atypical antipsychotic medications: (1) utilization of and expenditure for these new agents by the NLPDP and (2) hospital utilization by persons suffering from schizophrenia. The study consisted of three phases of data collection: (1) at the beginning of restricted access (April 1, 1995 through March 31, 1996); (2) at the end of restricted access (January 1, 1998 through December 31, 1998); and (3) in the second year of open access (January 1, 2000 through December $31,2000)$. Hospital utilization was determined by measuring LOS, total hospital days and readmission rates, as well as the factors influencing LOS and time to readmission, using regression techniques.

\section{Antipsychotic medication utilization and expenditure}

We used NLPDP drug claims data to measure the utilization of and expenditures for antipsychotic medications during the study period. The database includes all pre- 
scriptions from all therapeutic categories reimbursed by the program and uses the American Hospital Formulary System (AHFS), a classification system that groups drugs according to their therapeutic use. The therapeutic category corresponding to the relevant products $(28: 16.08)$ was used to import data regarding antipsychotic drugs for the fiscal years 1995/1996 to 2002/2003 into an Excel database. These data permitted analysis of the utilization of individual pharmaceutical agents covered by the provincial drug plan as well as the amount paid by the program. Utilization was defined as the volume of prescriptions and type of antipsychotic medication reimbursed by the NLPDP. Because the NLPDP database does not accurately record the number of pills dispensed per prescription, it was not possible to determine the duration of treatment. All antipsychotic agents were grouped into one of two categories: atypical and conventional. The atypical antipsychotic agents considered in this study were clozapine, risperidone, olanzapine and quetiapine.

\section{Hospital utilization}

The hospital utilization portion of the study measured total number of admissions, LOS, total number of hospital days and time to readmission for those individuals who had a diagnosis of schizophrenia, received treatment for this illness and were subsequently discharged from acute care psychiatry.

The data source for the hospitalization analysis was the hospital medical charts of all patients older than 18 years who were discharged from all general and psychiatric hospitals in Newfoundland and Labrador with a diagnosis of schizophrenia (ICD-9 diagnosis codes of 295.0-295.9) (WHO 1977) during the three 12-month periods. Each admission to hospital was screened to determine whether it was related to the patient's psychiatric illness. This screening allowed the research team to capture all hospitalizations resulting from an exacerbation of schizophrenia (e.g., suicide attempts). Any admission not related to a patient's psychiatric diagnosis (e.g., patients admitted for the treatment of pneumonia with a secondary diagnosis of schizophrenia) was excluded from the analysis.

The LOS was calculated by subtracting the date of admission from the date of discharge. Transfers between hospitals were treated as a single episode of care, and LOS that exceeded 365 days were excluded. The first episode of care identified in each study year was considered the index admission for that year, and the first admission identified for the three study years was referred to as the study index admission. Kaplan-Meier methods were used to evaluate the LOS for each study year. LOS were compared using the log rank test statistic.

The cost per day in each hospital was obtained from the Department of Health and Community Services, Financial Services Division, Government of Newfoundland and Labrador. The average per diem costs for each hospital for 2000 were multiplied 
by the total number of days to calculate the total hospital costs for each study year. The year 2000 costs were applied so that any observed increases in costs would not be the result of inflation over that period.

The time to readmission was calculated by subtracting the date of discharge from the date of next admission. Patients were followed after each discharge and were censored at death or last follow-up. The time to readmission variable was recoded into a dichotomous outcome variable with two groups: those readmitted to hospital within 365 days of discharge and those who were not readmitted to hospital within 365 days of discharge.

Continuous variables were analyzed using one-way analysis of variance (ANOVA) or Student's t-test, when appropriate. Normal distributions of continuous variables were described with the mean and standard deviation; other distributions were transformed using logarithmic transformation and presented as medians. When continuous variables were found

... each chart was reviewed extensively to record the following data for each patient for each hospital admission: gender, age, education level attained ... to be significantly different among the three years, post hoc analyses were conducted to determine which years were significantly different using Tukey's test of significance. All categorical vari-

ables were recoded for computer analysis. Categorical variables were compared using cross-tabulations and chi-square statistics to evaluate significance.

\section{Factors affecting length of stay and readmission}

As multiple factors influence LOS and readmission, multivariable modelling techniques were utilized to examine the impact of study year, while taking account of other factors that influence these outcomes. Thus, each chart was reviewed extensively to record the following data for each patient for each hospital admission: gender, age, education level attained, source of income, first psychiatric hospitalization, substance abuse, suicidal ideation, mental status examination findings (thought disorder, perceptual disorder, affect disorder, disordered behaviour), discharge against medical advice (AMA), non-adherence with prescribed pharmacotherapy, number of previous psychiatric admissions, duration of disease, need for electroconvulsive therapy (ECT) and seclusion due to uncontrollable and/or violent behaviour. Other information included 
switching from a conventional antipsychotic agent to an atypical antipsychotic during an admission, the class of antipsychotic agent prescribed on discharge and the inpatient medications received. Given the change in access to atypical antipsychotic agents over the course of the study, an interaction term was created to measure the effect on LOS in each year of switching from a conventional antipsychotic to an atypical agent. The interaction term between year of admission and drug class switch was subsequently entered in the multivariable models.

Specifically, multivariable Cox proportional hazards regression analysis using a block entry of variables was employed to determine significant independent predictors of time to discharge (LOS). Only a patient's first admission during the study period was included in the model. Given that the Cox proportional hazards model provides the risk of discharge from hospital, the hazard ratios and $95 \%$ confidence intervals were inverted so as to present the results as the risk of an increased LOS.

Multivariable binary logistic regression modelling was then used to determine significant predictors of the probability of being readmitted within one year of discharge relative to not being readmitted within one year. All potential risk factors were entered into the model using a standard method in which all variables are entered at once. All variables were evaluated in relation to the dependent variable through use of partial correlation coefficients. LOS was included as an independent variable in the multivariable analysis for readmission.

The hospital data were analyzed in the Statistical Package for the Social Sciences $\left(\mathrm{SPSS}^{\oplus}\right.$ ) version 9.0 for Windows, and the level of significance was set at 0.05 . The data received from the NLPDP on reimbursement for antipsychotic medications were analyzed using Microsoft ${ }^{\ominus}$ Excel spreadsheets.

\section{Results}

\section{Antipsychotic medication utilization and expenditure}

Use of second-generation antipsychotics increased dramatically between 1995/96 and 2000/01. During this time, prescriptions for all antipsychotics reimbursed by the NLPDP grew $24 \%$ while expenditures increased by more than $459 \%$. Total government spending on all antipsychotics was approximately $\$ 900$ thousand in 1995/96; in 2000/01, this therapeutic category exceeded $\$ 4.1$ million, with the four atypical antipsychotic agents (clozapine, risperidone, olanzapine and quetiapine) accounting for $90.4 \%$ of this amount (Figure 1). As of 2003/04, the use of atypical antipsychotic medications was still on the rise: the NLPDP paid for 66,764 prescriptions for antipsychotic medications and spent more than $\$ 7.88$ million during that fiscal year, with the atypical antipsychotic agents making up $95.5 \%$ of this amount (Figure 1). 
FIGURE 1. NLPDP expenditures for atypical antipsychotic medications vs. conventional antipsychotic medications, 1994/95-2003/04

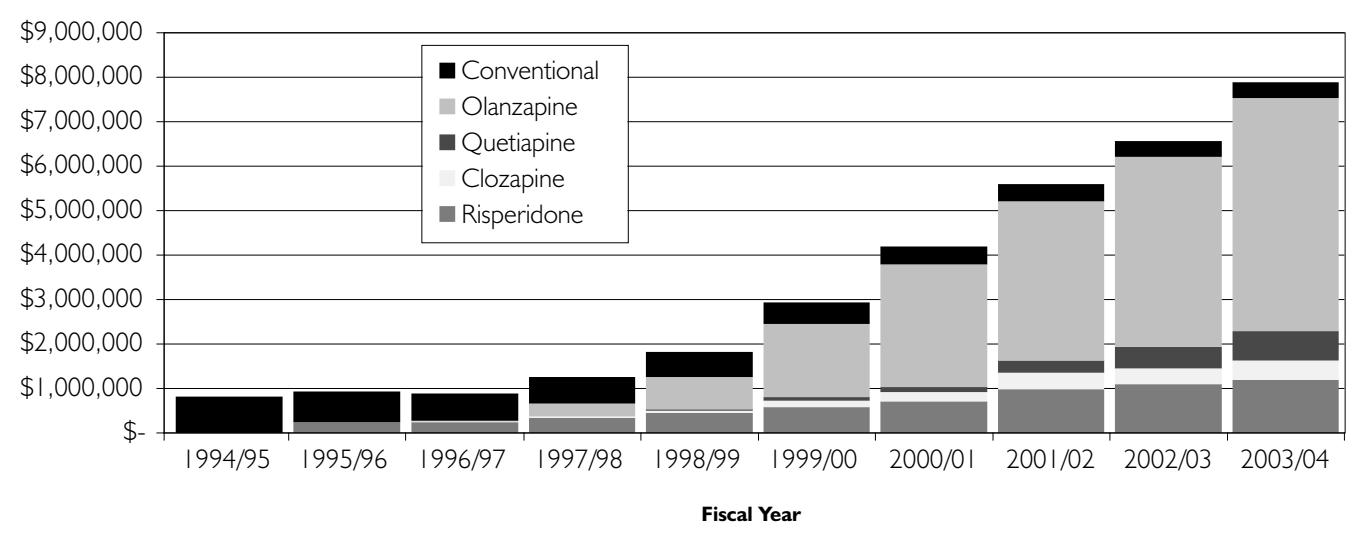

Despite this continued increase in the reimbursement for atypical antipsychotic medications, the number of persons eligible for the NLPDP declined by $17.2 \%$. While the number of cardholders in the seniors program remained constant, the number of cardholders in the social assistance program decreased (Figure 2). At the same time, while the number of prescriptions for antipsychotic medications reimbursed for the seniors' program decreased by $10.9 \%$, the number of prescriptions for the social assistance program increased by $31.3 \%$. Unfortunately, because the provincial drug database contains no patient-specific information (e.g., age, gender, diagnosis), it was not possible to link the data with any other information to determine indication for use or healthcare resource utilization.

FIGURE 2. Number of beneficiaries and total antipsychotic prescriptions reimbursed by NLPDP, 1995/96-2003/04

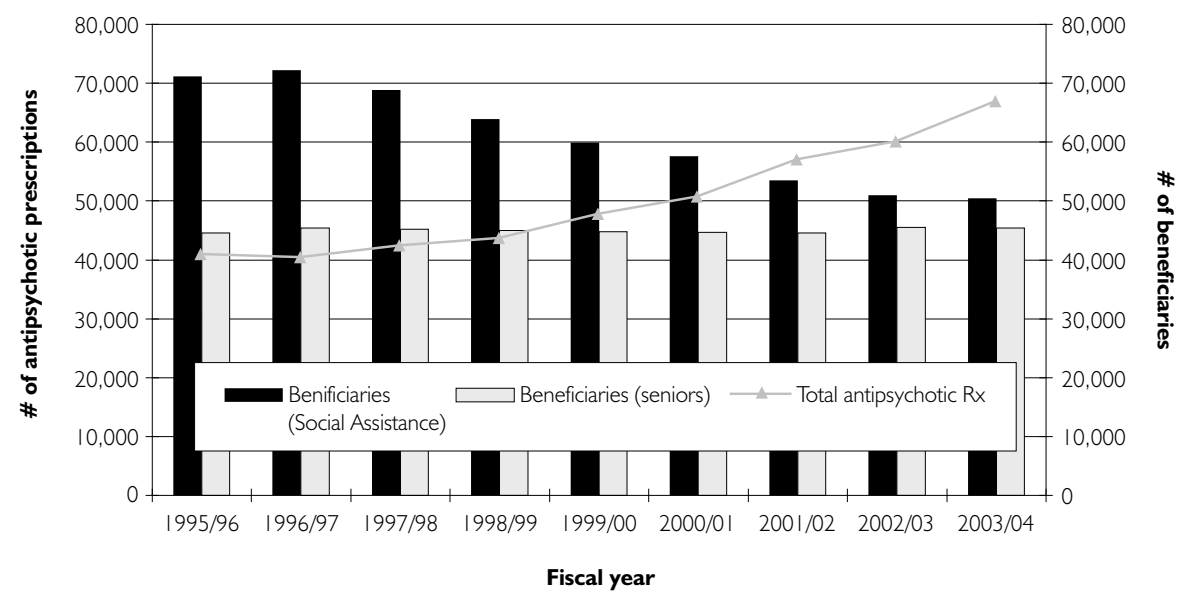




\section{Hospital utilization}

Three hundred and fourteen patients were admitted to hospital for the treatment of schizophrenia in Newfoundland in $1995 / 96$. The number decreased by $8.6 \%(\mathrm{n}=287)$ in 1998 and $18.2 \%(n=257)$ in 2000 compared to $1995 / 96$ (Table 1). The total number of unique patients in the three years of study was 645 , where $74.0 \%(n=477)$ appeared in one study year, $19.1 \%(\mathrm{n}=123)$ were admitted to hospital in two of the years and a small proportion $(7.0 \%, \mathrm{n}=45)$ were admitted to hospital in all three years. These 645 patients had 1,625 episodes of care resulting in a total of 47,098 hospital days. The mean number of episodes per patient per year was 1.9 (Table 1 ).

TABLE 1. Hospital utilization and costs for schizophrenia, Newfoundland and Labrador

\begin{tabular}{|c|c|c|c|c|}
\hline & Total & $1995 / 96$ & $\begin{array}{c}1998 \\
\text { (\% change } \\
\text { from '95/96) }\end{array}$ & $\begin{array}{c}2000 \\
\text { (\% change } \\
\text { from } 95 / 96 \text { ) }\end{array}$ \\
\hline Number of patients & 645 unique patients & 314 & $\begin{array}{c}287 \\
(-8.6 \%)\end{array}$ & $\begin{array}{c}257 \\
(-18.2 \%)\end{array}$ \\
\hline Episodes of care & 1,625 & 586 & $\begin{array}{c}551 \\
(-6.0 \%)\end{array}$ & $\begin{array}{c}488 \\
(-16.7 \%)\end{array}$ \\
\hline Hospital bed-days & 47,098 & 15,089 & $\begin{array}{l}16,318 \\
(+8.2 \%)\end{array}$ & $\begin{array}{c}|5,69| \\
(+4.0 \%)\end{array}$ \\
\hline Total hospital costs & $\$ 20,169,955$ & $\$ 6,474,095$ & $\begin{array}{l}\$ 7,080,065 \\
(+9.4 \%)\end{array}$ & $\begin{array}{l}\$ 6,615,795 \\
(+2.2 \%)\end{array}$ \\
\hline $\begin{array}{l}\text { Mean \# episodes per } \\
\text { patient per year (SD) }\end{array}$ & $\begin{array}{l}1.9 \\
(1.4)\end{array}$ & $\begin{array}{l}1.9 \\
(1.4)\end{array}$ & $\begin{array}{l}1.9 \\
(1.5)\end{array}$ & $\begin{array}{l}1.9 \\
(1.4)\end{array}$ \\
\hline $\begin{array}{l}\text { Median LOS per epi- } \\
\text { sode (min, } \max )\end{array}$ & $\begin{array}{c}18.0 \\
(1,336)\end{array}$ & $\begin{array}{c}15.0 \\
(1,319)\end{array}$ & $\begin{array}{c}19.0 \\
(1,336)\end{array}$ & $\begin{array}{l}22.0 *+ \\
(1,296)\end{array}$ \\
\hline $\begin{array}{l}\text { Median days per } \\
\text { patient (min, max) }\end{array}$ & $\begin{array}{c}36.0 \\
(1,372)\end{array}$ & $\begin{array}{c}32.0 \\
(1,369)\end{array}$ & $\begin{array}{c}40.0 \\
(1,336)\end{array}$ & $\begin{array}{l}40.5+\ddagger \\
(1,372)\end{array}$ \\
\hline $\begin{array}{l}\text { Total inpatient anti- } \\
\text { psychotic medication } \\
\text { costs }\end{array}$ & $\$ 425,885.45$ & $\$ 37,072$ & $\begin{array}{l}\$ 107,458 \\
(+189.9 \%)\end{array}$ & $\begin{array}{l}\$ 281,356 \\
(+658.9 \%)\end{array}$ \\
\hline
\end{tabular}

\footnotetext{
$*$ Significant at P-value $<0.001$

$\dagger=$ Based on log transformation

$\ddagger=$ Significant at $P$-value $<0.05$
} 
The number of episodes of care decreased by $6.0 \%$ in 1998 and by $16.7 \%$ in 2000 compared to the period when access was restricted (1995/96). However, relative to 1995/96, the number of hospital bed-days increased by $8.2 \%$ in 1998 and by $4.0 \%$ in 2000. Using an average per diem for each public acute care hospital in the province, these hospitalizations were estimated to cost $\$ 2.7$ million in 1995/96, $\$ 3.0$ million in 1998 and $\$ 2.5$ million in 2000. In addition, provincial psychiatric hospitalizations were estimated to cost $\$ 3.8$ million, $\$ 4.1$ million and $\$ 4.2$ million in 1995/96, 1998 and 2000, respectively.

The LOS per episode of care in 2000 and 1998 was longer than that in 1995/96, and based on the log transformation of LOS, this difference was statistically significant $(\mathrm{P}<0.001)$. There was a significant difference between the days per patient in each year as well. There were instances where the maximum value of the total number of days per patient per year exceeded 365 days. This finding is explained by the fact that a few patients were admitted to hospital prior to the study year but were discharged in the year of interest.

Of the 314 patients admitted to hospital for the treatment of schizophrenia during the baseline period (1995/96), 62.4\% were readmitted within one year of discharge. This proportion was not significantly different from the other two study years (59.2\% in 1998 and 58.6\% in 2000), although the trend was downward ( $\mathrm{P}=0.058)$ (Table 2). Fifty per cent of the population were readmitted within 215 days in 1995/96, 221 days in 1998 and 223 days in $2000(\mathrm{P}=0.114)$.

TABLE 2. Index admission analysis for readmission to hospital, Newfoundland and Labrador

\begin{tabular}{|l|c|c|c|c|}
\hline & $1995 / 96$ & 1998 & 2000 & P-value \\
\hline Median time to readmission (days) & 215 & 221 & 223 & $0.114+$ \\
\hline Readmitted within I year of discharge (\%) & 62.4 & 59.2 & 58.6 & 0.058 \\
\hline
\end{tabular}

$\dagger=$ Based on log transformation

\section{Patient characteristics}

Approximately two-thirds of the study population in each study year were male, about $72 \%$ of each group were receiving social assistance and close to half of the population had less than a grade 10 education (Table 3). The percentage of patients who discharged themselves against medical advice was $12.4 \%, 9.1 \%$ and $7.4 \%$ in 1995/96, 1998 and 2000, respectively. The proportion of patients recommended for ECT during their hospital admission increased from $5.7 \%$ to $9.0 \%$ over the study period. 
TABLE 3. Characteristics of schizophrenia patients admitted to hospital in Newfoundland and Labrador during each study year [percentages (numerator/denominator) of patients unless otherwise indicated]

\begin{tabular}{|c|c|c|c|}
\hline Characteristic & $\begin{array}{c}1995 / 96 \\
n=3 \mid 4\end{array}$ & $\begin{array}{c}1998 \\
n=287\end{array}$ & $\begin{array}{c}2000 \\
n=257\end{array}$ \\
\hline \multicolumn{4}{|l|}{ Sociodemographic } \\
\hline Male & $\begin{array}{c}66.6 \\
(209 / 314)\end{array}$ & $\begin{array}{c}69.3 \\
(199 / 287)\end{array}$ & $\begin{array}{c}70.8 \\
(182 / 257)\end{array}$ \\
\hline Median age in years (min, max) & $\begin{array}{c}37.0 \\
(17,85)\end{array}$ & $\begin{array}{c}39.0 \\
(16,88)\end{array}$ & $\begin{array}{c}41.0 \\
(18,83)\end{array}$ \\
\hline St. John's region & $\begin{array}{c}61.8 \\
(194 / 314)\end{array}$ & $\begin{array}{c}59.9 \\
(172 / 287)\end{array}$ & $\begin{array}{c}62.6 \\
(161 / 257)\end{array}$ \\
\hline$<$ Grade 10 education & $\begin{array}{c}47.9 \\
(\mid 46 / 305)\end{array}$ & $\begin{array}{c}49.3 \\
(135 / 274)\end{array}$ & $\begin{array}{c}47.5 \\
(1 \mid 5 / 242)\end{array}$ \\
\hline Social assistance & $\begin{array}{c}73.6 \\
(226 / 307)\end{array}$ & $\begin{array}{c}71.6 \\
(204 / 285)\end{array}$ & $\begin{array}{c}72.7 \\
(184 / 253)\end{array}$ \\
\hline \multicolumn{4}{|l|}{ Psychiatric Status } \\
\hline First psychiatric hospitalization & $\begin{array}{c}5.1 \\
(|6 / 3| 4)\end{array}$ & $\begin{array}{c}5.9 \\
(17 / 287)\end{array}$ & $\begin{array}{c}1.6 \\
(4 / 257) \\
\end{array}$ \\
\hline Substance abuse & $\begin{array}{c}32.3 \\
(98 / 303)\end{array}$ & $\begin{array}{c}29.6 \\
(85 / 287)\end{array}$ & $\begin{array}{c}30.0 \\
(77 / 257)\end{array}$ \\
\hline Suicidal ideation on admission & $\begin{array}{c}30.9 \\
(97 / 3 \mid 4)\end{array}$ & $\begin{array}{c}36.9 \\
(106 / 287)\end{array}$ & $\begin{array}{c}30.4 \\
(78 / 257)\end{array}$ \\
\hline Thought disorder & $\begin{array}{c}78.0 \\
(245 / 3 \mid 4)\end{array}$ & $\begin{array}{c}83.3 \\
(239 / 287)\end{array}$ & $\begin{array}{c}79.4 \\
(204 / 257)\end{array}$ \\
\hline Perceptual disorder & $\begin{array}{c}62.7 \\
(|97 / 3| 4)\end{array}$ & $\begin{array}{c}55.1 \\
(158 / 287)\end{array}$ & $\begin{array}{c}68.9 \\
(177 / 257)\end{array}$ \\
\hline Affect disorder & $\begin{array}{c}83.1 \\
(26|/ 3| 4)\end{array}$ & $\begin{array}{c}86.8 \\
(249 / 287)\end{array}$ & $\begin{array}{c}91.4 \\
(235 / 257)\end{array}$ \\
\hline Disordered behaviour & $\begin{array}{c}2.9 \\
(9 / 3 \mid 4)\end{array}$ & $\begin{array}{c}4.2 \\
(12 / 287)\end{array}$ & $\begin{array}{c}1.2 \\
(3 / 257)\end{array}$ \\
\hline \multicolumn{4}{|l|}{ Clinical Characteristics } \\
\hline Non-adherent with medication & $\begin{array}{c}54.0 \\
(|57 / 29|)\end{array}$ & $\begin{array}{c}49.1 \\
(|4| / 287)\end{array}$ & $\begin{array}{c}52.8 \\
(|3| / 248)\end{array}$ \\
\hline $\begin{array}{l}\text { Median \# previous admissions } \\
\text { (min, max) }\end{array}$ & $\begin{array}{l}7.0 \\
(1,85)\end{array}$ & $\begin{array}{l}8.0 \\
(1,91)\end{array}$ & $\begin{array}{l}10.0 \\
(1,94)\end{array}$ \\
\hline
\end{tabular}


TABLE 3. Continued

\begin{tabular}{|c|c|c|c|}
\hline Characteristic & $\begin{array}{c}1995 / 96 \\
n=314\end{array}$ & $\begin{array}{c}1998 \\
n=287\end{array}$ & $\begin{array}{c}2000 \\
n=257\end{array}$ \\
\hline $\begin{array}{l}\text { Median \# years of disease suffering } \\
\text { (min, max) }\end{array}$ & $\begin{array}{c}12 \\
(0,52) \\
n=307\end{array}$ & $\begin{array}{c}13.5 \\
(0,53) \\
n=284\end{array}$ & $\begin{array}{c}14.5 \\
(0,59) \\
n=25 \mid\end{array}$ \\
\hline Discharged against medical advice & $\begin{array}{c}12.4 \\
(39 / 3 \mid 4)\end{array}$ & $\begin{array}{c}9.1 \\
(26 / 287)\end{array}$ & $\begin{array}{c}7.4 \\
(19 / 257)\end{array}$ \\
\hline \multicolumn{4}{|l|}{ Level of Care } \\
\hline Recommended for ECT & $\begin{array}{c}5.7 \\
(|8 / 3| 4)\end{array}$ & $\begin{array}{c}7.7 \\
(22 / 287)\end{array}$ & $\begin{array}{c}9.0 \\
(23 / 257)\end{array}$ \\
\hline Seclusion & $\begin{array}{c}12.7 \\
(40 / 3 \mid 4)\end{array}$ & $\begin{array}{c}13.2 \\
(38 / 287)\end{array}$ & $\begin{array}{c}9.3 \\
(24 / 257)\end{array}$ \\
\hline \multicolumn{4}{|l|}{ Pharmacotherapy } \\
\hline Atypical prescribed on discharge & $\begin{array}{c}16.0 \\
(47 / 293)\end{array}$ & $\begin{array}{c}50.8 \\
(136 / 268)\end{array}$ & $\begin{array}{c}77.5 \\
(183 / 236)\end{array}$ \\
\hline
\end{tabular}

The inpatient chart review revealed that about half of patients admitted to hospital were non-adherent with prescribed medications on admission in each year. One-third of the population expressed suicidal ideation, and approximately $30 \%$ were substance abusers. Sixteen (5.1\%) and seventeen (5.9\%) patients experienced their first psychiatric admission to hospital during 1995/96 and 1998 study years. However, the number of first psychotic episodes in 2000 was significantly lower, with only four patients (1.6\%).

Forty-seven patients (16.0\%) in the baseline population (1995/96) were discharged on an atypical antipsychotic medication following the index admission, compared to $183(77.5 \%)$ in 2000. This increase in atypical use corresponds with both the introduction of two more atypical agents (olanzapine in October 1996 and quetiapine in December 1997) and the initiation of the unrestricted-access policy in December 1998. The number of patients admitted and discharged on an atypical antipsychotic medication increased substantially from baseline to the final study year. At the same time, the median LOS for these patients increased from 13.0 days to 31.0 days, a difference of 18.0 days. In contrast, the number of patients who were switched from a traditional antipsychotic to an atypical antipsychotic medication while in hospital remained relatively small in each study year, indicating that most patients were switched as outpatients. The median time spent in hospital for these 47 patients was 72.5 days, 40.0 days and 29.5 days in 1995/96, 1998 and 2000, respectively. 
FACTORS ASSOCIATED WITH LENGTH OF STAY

The multivariable Cox proportional hazards model to determine the independent predictors of LOS included 78.9\% (509/645) of the original population, owing to missing information for some variables for the 136 excluded patients. Of the 19 variables that were entered in the model, six were found to significantly influence the amount of time a patient remained in hospital (Table 4).

TABLE 4. Multivariable Cox proportional hazards model of the independent variables predicting an increased LOS by study index admission, for 1995/96, 1998 and 2000 ( $\mathrm{n}=509 / 645,78.9 \%)$

\begin{tabular}{|c|c|c|c|}
\hline Characteristic & Hazard Ratio & $95 \% \mathrm{Cl}$ & P-value \\
\hline \multicolumn{4}{|l|}{ Sociodemographic } \\
\hline Male & 0.82 & $0.22-1.02$ & 0.074 \\
\hline Age & 1.01 & $0.99-1.02$ & 0.400 \\
\hline$<$ Grade 10 education & 0.90 & $0.74-1.08$ & 0.258 \\
\hline $\begin{array}{l}\text { Year of admission } \\
1995 \text { vs. } 2000 \\
1998 \text { vs. } 2000\end{array}$ & $\begin{array}{l}0.77 \\
0.81\end{array}$ & $\begin{array}{l}0.59-1.01 \\
0.61-1.07\end{array}$ & $\begin{array}{l}0.056 \\
0.143\end{array}$ \\
\hline Social assistance & 1.01 & $0.81-1.25$ & 0.949 \\
\hline \multicolumn{4}{|l|}{ Psychiatric Status } \\
\hline First psychiatric hospitalization & 1.15 & $0.74-1.78$ & 0.547 \\
\hline Substance abuse & 0.99 & $0.80-1.22$ & 0.918 \\
\hline Suicidal ideation & 0.71 & $0.58-0.87$ & $0.0009 *$ \\
\hline Thought disorder & 1.42 & $1.11-1.82$ & $0.006 *$ \\
\hline Perceptual disorder & 1.00 & $0.82-1.22$ & 0.995 \\
\hline Affect disorder & 1.16 & $0.90-1.50$ & 0.260 \\
\hline Disordered behaviour & 1.35 & $0.78-2.34$ & 0.286 \\
\hline \multicolumn{4}{|l|}{ Clinical Characteristics } \\
\hline Non-adherent with medication & 1.05 & $0.86-1.05$ & 0.634 \\
\hline \# previous admissions & 1.00 & $0.98-1.01$ & 0.322 \\
\hline \# years of disease suffering & 1.00 & $0.99-1.02$ & 0.612 \\
\hline Discharged against medical advice & 0.40 & $0.28-0.56$ & $<\left.0.00\right|^{*}$ \\
\hline
\end{tabular}


TABLE 4. Continued

\begin{tabular}{|l|c|c|c|}
\hline Characteristic & Hazard Ratio & $95 \%$ Cl & P-value \\
\hline Level of Care & 2.58 & $1.75-3.80$ & $<0.001 *$ \\
\hline Recommended for ECT & 1.93 & $1.45-2.57$ & $<0.001 *$ \\
\hline Seclusion & 1.26 & $0.74-2.14$ & 0.401 \\
\hline Pharmacotherapy & 2.61 & $\begin{array}{l}1.12-6.11 \\
0.81-3.25\end{array}$ & $\begin{array}{c}0.027 * \\
0.170\end{array}$ \\
\hline Drug switch (conventional to atypical) & 1.62 &
\end{tabular}

* $=$ Significant at $P$-value $<0.05$

Given the change in access to atypical antipsychotic agents over the course of the study, an interaction term was created to measure the effect on LOS (in each year) of switching from a conventional antipsychotic to an atypical antipsychotic medication. The effect of switching in 1995/96 was shown to significantly increase LOS compared to the effect of switching in 2000 (hazard ratio $2.61,95 \% \mathrm{CI}=1.12-6.11 ; \mathrm{P}=0.027$ ). Independent of age and gender, requiring ECT (hazard ratio $2.58,95 \% \mathrm{CI}=1.75-$ 3.80; $\mathrm{P}<0.001$ ), seclusion (hazard ratio $1.93,95 \% \mathrm{CI}=1.45-2.57 ; \mathrm{P}<0.001$ ) and having thought disorder (hazard ratio $1.42,95 \% \mathrm{CI}=1.11-1.82 ; \mathrm{P}=0.006$ ) significantly increased a patient's time in hospital. Suicidal ideation on admission (hazard ratio 0.71, $95 \% \mathrm{CI}=0.58-0.87 ; \mathrm{P}=0.0009$ ) and discharging oneself against medical advice (hazard ratio $0.40,95 \% \mathrm{CI}=0.28-0.56 ; \mathrm{P}<0.001$ ) were significant predictors of a reduced LOS. Factors that failed to affect LOS included years since first diagnosis, number of previous hospitalizations, first psychiatric hospitalization, substance abuse, perceptual disorder, affect disorder, disordered behaviour, low education, non-adherence with prescribed medication on admission and receiving social assistance.

\section{FACTORS ASSOCIATED WITH READMISSION TO HOSPITAL}

A multivariable logistic regression model was used to determine the predictors of rehospitalization. The model included $81.5 \%$ (521/639) of the entire study population and revealed two significant, independent predictors for re-hospitalization within 12 months of discharge: leaving hospital against medical advice $(\mathrm{OR}=2.59,95 \% \mathrm{CI}=$ $1.12-6.02 ; \mathrm{P}=0.027)$ and previous hospital admissions. For every additional previous admission there was a $5 \%$ increase in the likelihood that the patient would be read- 
mitted $(\mathrm{OR}=1.05,95 \% \mathrm{CI}=1.03-1.08 ; \mathrm{P}=0.002)$ (Table 5). Contrary to expectation, neither non-adherence with prescribed medications on the previous admission nor receiving a prescription for an atypical antipsychotic medication on last discharge influenced the probability of readmission to hospital within one year of discharge.

TABLE 5. Multivariable logistic regression model for predictors influencing hospitalization within one year of discharge from the index admission 1995/96, 1998 and $2000(\mathrm{n}=521 / 639,81.5 \%)$

\begin{tabular}{|c|c|c|c|}
\hline Characteristic & Odds Ratio & $95 \% \mathrm{Cl}$ & $P$-value \\
\hline \multicolumn{4}{|l|}{ Sociodemographic } \\
\hline Male & 0.65 & $0.42-1.01$ & 0.057 \\
\hline Age in years & 0.98 & $0.96-1.01$ & 0.138 \\
\hline$<$ Grade 10 education & 1.32 & $0.89-1.96$ & 0.169 \\
\hline $\begin{array}{l}\text { Year of admission } \\
1995 \text { vs. } 2000 \\
1998 \text { vs. } 2000\end{array}$ & $\begin{array}{l}1.09 \\
0.54\end{array}$ & $\begin{array}{l}0.39-3.07 \\
0.18-1.62\end{array}$ & $\begin{array}{l}0.875 \\
0.272\end{array}$ \\
\hline Social assistance & 1.06 & $0.69-1.62$ & 0.787 \\
\hline \multicolumn{4}{|l|}{ Psychiatric Status } \\
\hline First psychiatric hospitalization & 1.24 & $0.53-2.89$ & 0.627 \\
\hline Substance abuse & 1.53 & $0.99-2.36$ & 0.058 \\
\hline Suicidal ideation on admission & 1.26 & $0.82-1.93$ & 0.292 \\
\hline Thought disorder & 1.01 & $0.61-1.68$ & 0.962 \\
\hline Perceptual disorder & 1.07 & $0.7 \mid-1.60$ & 0.749 \\
\hline Affect disorder & 0.77 & $0.45-1.33$ & 0.346 \\
\hline Disordered behaviour & 0.77 & $0.25-2.40$ & 0.658 \\
\hline \multicolumn{4}{|l|}{ Clinical Characteristics } \\
\hline Non-adherent with medication & 1.08 & $0.72-1.63$ & 0.699 \\
\hline \# previous admissions & 1.05 & $1.03-1.08$ & $0.002 *$ \\
\hline Index length of stay & 1.00 & $0.99-1.00$ & 0.504 \\
\hline \# years of disease suffering & 1.00 & $0.98-1.03$ & 0.764 \\
\hline Discharged against medical advice & 2.59 & $1.12-6.02$ & $0.027 *$ \\
\hline
\end{tabular}


TABLE 5. Continued

\begin{tabular}{|l|c|c|c|}
\hline Characteristic & Odds Ratio & $95 \%$ Cl & P-value \\
\hline Level of Care & \multicolumn{3}{|l|}{} \\
\hline Recommended for ECT & 0.70 & $0.32-1.53$ & 0.372 \\
\hline Seclusion & 0.78 & $0.43-1.44$ & 0.434 \\
\hline Pharmacotherapy & 1.14 & $0.38-3.39$ & 0.819 \\
\hline Atypical on discharge & 1.10 & $0.30-4.09$ & 0.889 \\
\hline Year of admission* discharge drug class & 1.36 & $0.39-4.80$ & 0.631 \\
\hline 1995/96 vs. 2000 & &
\end{tabular}

* = Significant at $P$-value $<0.05$

\section{Discussion}

This study was designed to test the hypothesis that access to a new technology (i.e., atypical antipsychotic medications) would keep people out of hospital, or permit earlier discharge. The atypical drugs do not themselves have better outcomes in terms of disease improvement but do reduce certain side effects. Such reduction might improve adherence with treatment that may change outcomes and thus create overall system savings. Results of this study demonstrate that unrestricted access to new atypical antipsychotic agents did not coincide with a reduction in total days in hospital or readmission rates for persons suffering from schizophrenia.

The current study has several limitations. Hospital readmission was used as a method of measuring patient outcome influenced by antipsychotic therapy. While objective and not prone to error, readmission may not be the best measure of outcome for schizophrenia from a patient's or caregiver's perspective. Subtle differences in time to subjective improvements in extreme psychotic behaviour or ability to gain employment may have been more relevant indicators of effectiveness. The perspective of the patient receiving the therapy is essential in determining its value; however, such exploration was beyond the scope of this study. If these outcomes had been assessed, differences associated with drug therapy may have been revealed.

Additionally, the risk of readmission was determined by dichotomizing a variable originally measured as a continuous variable. The authors realize that answering the question "When?" may be much more illuminating than answering "Whether?" an event occurred. Splitting the population eliminates potentially meaningful variation in event times by clustering together everyone who gets readmitted before, and after, the chosen cut-off. For example, persons who were readmitted within one month were not distinguished from those readmitted within 11 months. The decision to ask whether 
a patient gets readmitted rather than when was primarily based on the fact that the selected cut-off time was significant from a policy perspective. Moreover, a survival analysis of time to readmission in days was less informative because even in the presence of censoring, the median time to readmission was greater than 250 days. As a result, it was felt that no meaningful variation in event times was lost. Cutting the data into numerous categories, however, makes it more difficult to interpret the results, as our goal was to model the probability of having an event.

Another limitation has to do with the predictor variables included in the study. It is possible that the variables themselves were not sensitive enough to detect changes in LOS or readmission risk. For example, the dichotomous variable indicating the presence or absence of thought disorder may not accurately represent the severity of the disorder; there may be a continuum of severity. Even if all relevant clinical information was abstracted from the chart, there are numerous non-clinical factors that can influence the need for admission to hospital and LOS that were not addressed in this study (e.g., physician factors that affect treatment practices). Placement problems, caregiver stress or an unsupportive living environment may result in the need for hospitalization and extend a person's LOS. There is evidence in the literature that a patient's living situation or lack of support are important predictors of LOS and frequent hospitalizations (Creed et al. 1997; Laessle et al. 1988; Gordon et al. 1985; Cyr and Haley 1983; Falloon et al. 1987; Caton et al. 1984). Clinicians may be reluctant to discharge patients who live unsupported in the community.

The newer atypical antipsychotic medications have been linked to improved medication adherence (Glazer and Johnstone 1997; Kane 1999; Lindstrom and Bingefors 2000; Chakos et al. 2001). However, the rate of adherence measured in this study among those patients admitted to hospital was not altered with the increased utilization of atypical antipsychotic medications. Non-adherence measured in this study may, in fact, underestimate the actual rate because of our reliance on written documentation of non-adherence in patients' charts and may partly explain why non-adherence was not found to be a significant predictor of recidivism in the current study.

Even if adherence rates could be accurately measured, the improved adverse effect profiles of atypical antipsychotic medications may be only part of the reason for continuing drug therapy. Literature suggests that there are other powerful predictors contributing to low adherence to schizophrenia treatment: patient-related factors (e.g., substance abuse); family-related factors (e.g., alienation from the patient); diseaserelated factors (e.g., lack of insight into the disorder); and healthcare system and community support services (e.g., family therapy, community-based services and general help with adherence strategies) may play a role in improving outcomes (Marder 1998; Kampman and Lehtinen 1999; Carpenter and Tamminga 1995; Cuffel et al. 1996; Kemp and David 1996; Agarwal et al. 1998; Dixon et al. 1997). An in-depth review of the community programs offered to persons with schizophrenia in Newfoundland 
and Labrador and the effectiveness of these programs on this population was not undertaken in this project but would have helped to interpret some of the findings and thus provided valuable information for policy makers. At the same time, it should be emphasized that the goal of this study was to examine the rationale used in making the decision to replace restricted access with an open-access program: the possibility that increased costs of atypical agents would be offset by decreased hospitalization for schizophrenia.

The unrestricted-access policy was implemented during a period of rapid change in the healthcare system, particularly in the St. John's region. Changes in hospital admission policies, access to housing, bed availability, demands on community resources and physician practice could influence hospital utilization. While total separations decreased, the average LOS for schizophrenia increased by $46.7 \%$ between 1995 and 2000 (the overall provincial average LOS for all hospital admissions increased by only $2.6 \%$ [CIHI 2003]) and the number of acute care beds in the mental health program in the St. John's region decreased by about 7\% from 1995/96 to 1999/2000 (personal communication, Mary Dwyer, Program Director, Mental Health Program, St. John's, June 2006). At the same time, the outpatient services provided by the Community Care Program and accessibility to them remained stable. It is possible that liberalized access to the new medications kept a higher proportion of schizophrenia sufferers out of hospital and thus opened up space for the more severely compromised patients, allowing them to be treated more intensively. This possibility is consistent with some of the changes in clinical characteristics of the patients over the time periods (e.g., an increased proportion requiring ECT). However, because the time to readmission was not significantly different for each of the study periods, the drugs did not affect time spent in the community.

An important contribution this study makes is that it highlights the limitations in the information infrastructure in the province of Newfoundland and Labrador at the time the research was conducted. The study provides an indication of significant findings and would be enhanced if there were better linkage capabilities between actual drug use, healthcare resource utilization and health outcomes. Fortunately, the Newfoundland and Labrador Centre for Health Information has been created whose mandate is to ensure the availability of high-quality health information for healthcare, systemwide planning, research and policy development. The Centre is responsible for the development and management of a provincewide Health Information Network. As a result, future research in the area of drug policy can be conducted more efficiently with better data (e.g., patient-specific drug exposure) (personal communication, Donald MacDonald, Director of Research and Evaluation, Newfoundland and Labrador Centre for Health Information, St. John's, June 2006). 


\section{Conclusions}

Two findings are worth noting. First, there was no appreciable change in the rate of adherence as measured in this study. Yet, the share of patients receiving atypical agents increased dramatically. Thus, part of the hypothesis fails: access alone does not ensure adherence with therapy. It is acknowledged, however, that adherence was measured only among those patients admitted to hospital, not among all recipients of such medicines. Second, there was a $24 \%$ increase in prescriptions filled. While we do not know what that increase means in terms of length of prescription, it might be reasonable to assume that the length for conventional and atypical agents is about the same. Thus, the volume of treatment probably increased by about $24 \%$. This implies that the maximum gain in the "process" of care is $24 \%$. The financial implication of this increase in process is a more than $400 \%$ increase in costs. There are very few processes in healthcare or elsewhere in society that will generate a return of almost 20-fold. Thus, the logic of the return on investment argument in support of unrestricted access to atypical antipsychotic medications is arguably a fantasy. This claim is substantiated by the fact that the increase in government expenditure for these drugs did not coincide with a decrease in acute care hospital utilization in the province by patients with schizophrenia. Although a decrease in hospital admissions occurred, any associated cost savings were negated by an increase in LOS.

Despite our not having patient-specific drug exposure data, the results still address the issue of the overall system-level return on investment from spending on this drug category. It is, after all, that return that is often used to justify the very high cost of atypical agents: spend many times more on the newer medicines and the savings will accrue in the hospital sector. In this case, the return on investment motivation appears to have been misguided. Further research may be warranted to examine impacts on the system and patient benefits that were not assessed in this study and to determine whether targeted access may be prudent policy for drug categories of this sort.

A noteworthy impact of the current study is that the results were used by the NLPDP in its review of the atypical antipsychotic class of medications. In the months following the submission of the report, a decision was made to change the policy surrounding the coverage status of these medications. Effective October 1, 2004, the new policy consisted of partial restriction. It was decided that open benefit status was to remain in place for risperidone and quetiapine, thereby allowing first-line atypical coverage for schizophrenia and other approved indications. Olanzapine and clozapine were moved to Special Authorization and are considered for coverage where the former have failed.

Correspondence may be directed to: Daria O'Reilly, Program for Assessment of Technology in Health, 25 Main Street West, Suite 2000, Hamilton, ON L8P 1H1; tel. 905-523-7284 ext. 5277; fax: 905-522-0568; e-mail: oreilld@mcmaster.ca. 


\section{ACKNOWLEDGMENTS}

Funded by an unrestricted, joint educational grant from AstraZeneca Canada Inc., Eli Lilly Canada Inc., Janssen-Ortho Inc. and Novartis Pharmaceuticals Canada Inc. Dr. Parfrey holds a CIHR-RPP Distinguished Scientist Award. Study design, data collection, analysis and interpretation, and the writing of any reports were the sole responsibility of the authors.

\section{REFERENCES}

Agarwal, M.R., V.K. Sharma, K.V. Kishore Kumar and D. Lowe. 1998. "Non-Compliance with Treatment in Patients Suffering from Schizophrenia: A Study to Evaluate Possible Contributing Factors." International Journal of Social Psychiatry 44(2): 92-106.

Baldwin, D. and S. Montgomery. 1995. "First Clinical Experience with Olanzapine: Results of an Open-Label Safety and Dose-Ranging Study in Patients with Schizophrenia." International Clinical Psychopharmacology 10: 239-44.

Beasley, C.M., M.A. Dellva, R.N. Tamura, H. Morgenstern, W.M. Glazer, K. Ferguson et al. 1999. "Randomised Double-Blind Comparison of the Incidence of Tardive Dyskinesia in Patients with Schizophrenia During Long-Term Treatment with Olanzapine or Haloperidol." British Journal of Psychiatry 174: 23-30.

Canadian Institute for Health Information (CIHI). 2003. “Table 4. Average Length of Hospital Stay (in Days) for Canada, Provinces and Territories, 1995/96, 2000/01 and 2001/02." Rate of Hospitalizations Continues to Decline But Average Length of Stay Is Increasing Slightly, Reports CIHI. Retrieved July 10, 2007. <http://secure.cihi.ca/cihiweb/en/media_19nov2003_tab4_ e.html>.

Carpenter, W.T. Jr. and C.A. Tamminga. 1995. "Why Neuroleptic Withdrawal in Schizophrenia?” Archives of General Psychiatry 52(3): 192-93.

Caton, C.L., J.M. Goldstein, O. Serrano and R. Bender. 1984. “The Impact of Discharge Planning on Chronic Schizophrenic Patients." Hospital E Community Psychiatry 35(3): 255-62.

Chakos, M., J. Lieberman, E. Hoffman, D. Bradford and B. Sheitman. 2001. "Effectiveness of Second-Generation Antipsychotics in Patients with Treatment-Resistant Schizophrenia: A Review and Meta-analysis of Randomized Trials." American Journal of Psychiatry 158(4): 518-26.

Creed, F., B. Tomenson, P. Anthony and M. Tramner. 1997. "Predicting Length of Stay in Psychiatry." Psychological Medicine 27(4): 961-66.

Cuffel, B.J., J. Alford, E.P. Fischer and R.R. Owen. 1996. "Awareness of Illness in Schizophrenia and Outpatient Treatment Adherence." Journal of Nervous and Mental Disorders 184(11): 653-59.

Cyr, J.J. and G.A. Haley. 1983. "Use of Demographic and Clinical Characteristics in Predicting Length of Psychiatric Hospital Stay: A Final Evaluation." Journal of Consulting and Clinical Psychology 51(4): 637-40.

Dixon, L., P. Weiden, M. Torres and A. Lehman. 1997."Assertive Community Treatment and Medication Compliance in the Homeless Mentally Ill," American Journal of Psychiatry 154(9): 1302-4.

Falloon, I.R., C.W. McGill, J.L. Boyd and J. Pederson. 1987. "Family Management in the Prevention of Morbidity of Schizophrenia: Social Outcome of a Two-Year Longitudinal Study." Psychological Medicine 17(1): 59-66. 
Glazer, W.M. and B.M. Johnstone. 1997. "Pharmacoeconomic Evaluation of Antipsychotic Therapy for Schizophrenia." Journal of Clinical Psychiatry 58 (Suppl. 10): 50-54.

Goeree, R., F. Farahati, N. Burke, G. Blackhouse, D. O’Reilly, J. Pyne et al. 2005."The Economic Burden of Schizophrenia in Canada in 2004." Current Medical Research and Opinion 21(12): 2017-28.

Goeree, R., B.J. O’Brien, P. Goering, G. Blackhouse, K. Agro, A. Rhodes et al. 1999.“The Economic Burden of Schizophrenia in Canada." Canadian Journal of Psychiatry 44(5): 464-72.

Gordon, R.E., J. Vijay, S.G. Sloate, R. Burket and K.K. Gordon. 1985. "Aggravating Stress and Functional Level As Predictors of Length of Psychiatric Hospitalization." Hospital E Community Psychiatry 36(7): 773-74.

Hafner, H. and W. der Heiden. 1997. "Epidemiology of Schizophrenia." Canadian Journal of Psychiatry 42(2): 139-51.

Kampman, O. and K. Lehtinen. 1999. “Compliance in Psychoses." Acta Psychiatrica Scandinavica 100(3): 167-75.

Kane, J. 1999. “Olanzapine in the Long-Term Treatment of Schizophrenia." British Journal of Psychiatry Supplement 37: 26-29.

Kemp, R. and A. David. 1996."Psychological Predictors of Insight and Compliance in Psychotic Patients." British Journal of Psychiatry 169(4): 444-50.

Laessle, R.G., A. Yassouridis and H. Pfister. 1988. “Sociodemographic Characteristics and Length of Psychiatric Hospital Stay: Application of a Proportional Hazards Model.” Acta Psychiatrica Scandinavica 77(3): 349-51.

Lieberman, J.A., T.S. Stroup, J.P. McEvoy, M.S. Swartz, R.A. Rosenheck, D.O. Perkins et al. 2005. "Effectiveness of Antipsychotic Drugs in Patients with Chronic Schizophrenia." New England Journal of Medicine 353(12): 1209-23.

Lindstrom, E. and K. Bingefors. 2000. "Patient Compliance with Drug Therapy in Schizophrenia. Economic and Clinical Issues." Pharmacoeconomics 18(2): 106-24.

Marder, S.R. 1998. "Facilitating Compliance with Antipsychotic Medication." Journal of Clinical Psychiatry 59 (Suppl. 3): 21-25.

Oh, P., T. Einarson, M. Iskedjian, A. Addis and K. Lanctot. 1996. Pharmacoeconomic Evaluation of Schizophrenia: Clozapine in Treatment-Resistant Schizophrenia and Risperidone in Chronic Schizophrenia. Ottawa: Canadian Coordinating Office for Health Technology Assessment.

Schillevoort, I., A. de Boer, R.M. Herings, R.A. Roos, P.A. Jansen and H.G. Leufkens. 2001. "Risk of Extrapyramidal Syndromes with Haloperidol, Risperidone, or Olanzapine." Annals of Pharmacotherapy 35(12): 1517-22.

Tran, P.V., M.A. Dellva, G.D. Tollefson, C.M. Beasley Jr., J.H. Potvin and G.M. Kiesler. 1997.

"Extrapyramidal Symptoms and Tolerability of Olanzapine versus Haloperidol in the Acute Treatment of Schizophrenia." Journal of Clinical Psychiatry 58(5): 205-11.

World Health Organization (WHO). 1977. Manual of the International Statistical Classification of Diseases, Injuries and Causes of Death (9th rev.). Geneva: Author. 